\title{
EDUCAÇÃO FÍSICA, PEDAGOGIA CRIITICA E IDEOLOGIA: GÊNESE E INTERPRETAÇÕES
}

PHYSICAL EDUCATION, CRITICAL PEDAGOGY AND IDEOLOGY: GENESIS AND INTERPRETATIONS

\author{
EDUCACIÓN FÍSICA, PEDAGOGÍA CRÍTICA E IDEOLOGÍA: GÉNESIS \\ E INTERPRETACIONES
}

Felipe Quintão de Almeida*, Valter Bracht *, Alexandre Fernandez Vaz ${ }^{* *}$

\begin{abstract}
Palavras-chave Educação. Epistemologia. Artigo de revista. Marxismo.

Resumo: Descreve os contornos da produção crítica em Educação Física explicitamente influenciada, a partir dos anos 1980, pela pedagogia histórico-crítica. Reflete sobre os fundamentos da crítica ideológica em Educação Física, ocasião para dialogar com as interpretações que John Thompson e Paul Ricoeur fizeram desse conceito na tradição marxista. Em termos metodológicos, a análise toma como fonte os artigos da Revista Brasileira de Ciências do Esporte, da revista Movimento, da revista Motrivivência e da revista Pensar a Prática, publicados entre 1979 e 2010. Conclui com as dificuldades dessa compreensão da crítica ideológica em Educação Física, situando o leitor sobre a continuidade da investigação.
\end{abstract}

Abstract: This paper describes the framework of critical thinking in Brazilian Physical Education that was influenced after the 1980s by "Critical and Historical Pedagogy". The paper reflects on the basis of ideological critique in Physical Education in a dialogue with by Paul Thompson's and Paul Ricouer's views on that concept under Marxist tradition. Its sources are papers published between 1979 and 2010 in four scientific journals: Revista Brasileira de Ciências do Esporte, Movimento, Motrivivência and Pensar a Prática. The paper concludes with a discussion about some difficulties to understand that ideological critique in Physical Education and proposes more research.

Resumen: Describe los contornos de la producción crítica en la Educación Física

Palabras clave Educación. Epistemología. Artículo de revista. Marxismo. explícitamente influenciada, a partir de los años 1980, por la "Pedagogía HistóricoCrítica". Reflexiona sobre los fundamentos de la crítica ideológica en Educación Física, ocasión para dialogar con la interpretación que Paul Thompson y Paul Ricoeur hicieron de este concepto en la tradición marxista. En términos metodológicos, el análisis toma como fuente los artículos de las siguientes publicaciones: Revista Brasileira de Ciências do Esporte, revista Movimento, revista Pensar a Prática y revista Motrivivência, publicados entre 1979 y 2010. Concluye con las dificultades de esa comprensión de crítica ideológica en la Educación Física, situando al lector a respecto de la continuidad de la investigación.
*Universidade Federal do Espírito Santo. Vitória, ES, Brasil. E-mail: fqalmeida@hotmail.com

**Universidade Federal de Santa Catarina. Florianópolis, SC, Brasil. E-mail: alexfvaz@uol.com.br

Recebido em: 21-07-2014 Aprovado em: 23-01-2015 (c) (1) (8) Licence 


\section{INTRODUÇÃOO}

Este artigo oferece uma descrição da produção crítica em Educação Física, em especial daquela que foi influenciada a partir dos anos 1980 pela pedagogia histórico-crítica (SAVIANI, 2008; 2009). 0 objetivo é caracterizar sua presença em artigos publicados em periódicos da área. Consideramos, para tanto, que a produção crítica na Educação Física brasileira está diretamente relacionada com aquilo que, em retrospectiva, tem-se chamado de Movimento Renovador. Embora inicialmente este Movimento se estruture como uma ampla frente que pretendia transformar a disciplina no sentido de conferir-lhe maior cientificidade, logo se fizeram sentir diferenças de entendimento da ciência e da relação entre ela e a política. A partir daí, e por influência de debates presentes no campo da Educação, um segmento se diz "progressista" ou "crítico". É a esse segmento que nos referimos neste artigo.

Analisamos, especificamente, os artigos publicados entre os anos de 1979 e 2010 que se enquadram nessa caracterização. 0 recorte temporal se justifica, pois é nesse período que uma pedagogia assim adjetivada efetivamente se constitui e se consolida. Consideramos, para tanto, quatro periódicos: Revista Brasileira de Ciências do Esporte (RBCE), Motrivivência, Movimento e Pensar a Prática. Em relação à $R B C E$, utilizamos 86 edições publicadas entre os anos de 1979 e 2010. Da Motrivivência, 31 edições entre 1988 e 2010. No que diz respeito à Movimento, as 46 edições publicadas entre 1994 e 2010. De Pensar a Prática, foram consultadas as 23 edições disponíveis entre 1998 e 2010. Depois de organizado 0 material, foram inventariados os textos que defendiam uma perspectiva crítica de Educação Física. Considerando os 31 anos abrangidos pela investigação, identificamos 117 trabalhos que, segundo a leitura dos resumos, poderiam servir aos propósitos do trabalho. A análise, na sequência, envolveu a leitura completa dos textos, quando foi feita uma categorização temática. A descrição analítica daí resultante foi desenvolvida a partir de um confronto entre as fontes examinadas e as classificações já disponíveis na literatura, em especial as considerações de Dermeval Saviani nos dois livros (2008; 2009) em que estabeleceu os alicerces de sua pedagogia histórico-crítica.

Do total do material identificado, após a leitura de cada texto completo e análise de seu conteúdo (BARDIN, 1977), descartamos 52 e operamos, efetivamente, com os 65 restantes. Destes, decidimos analisar os que se relacionam a um dos principais objetivos da pedagogia aqui analisada: a crítica à ideologia. Isso significa dizer que este recorte prescindiu de textos que, entre os 65 elencados, não tinham como foco esse objetivo (crítica à ideologia), mas que estavam relacionados a outras dimensões dessa pedagogia. Considerando os limites interpostos para um artigo, este artigo utilizou, efetivamente, 42 produções (as que são listadas nas referências). Desta forma, há material analisado que se repete ao longo do texto, uma vez nele presente mais de uma questão analisada.

$\mathrm{O}$ artigo está organizado em duas partes. Na primeira apresentamos uma caracterização da pedagogia crítica em Educação Física, para, na segunda, oferecer uma leitura sobre a crítica à ideologia. Logo após, o texto se encerra com suas considerações finais. 


\section{DESCREVENDO A PEDAGOGIA CRÍTICA EM EDUCAÇÃO FÍSICA: A INFLUÊNCIA MARXISTA}

O desenvolvimento de uma pedagogia crítica na Educação Física é tributário da influência que o materialismo histórico-dialético exerceu sobre alguns intelectuais do chamado Movimento Renovador. Essa tradição, todavia, não corresponde a um bloco homogêneo ou uniforme, pois "há marxismos e marxismos", como se costuma dizer. Nos anos 1980, teses e conceitos de Marx e de seguidores da tradição por ele iniciada foram conhecidos pela interpretação de autores do campo educacional. Nesse sentido, o desenvolvimento da pedagogia histórico-crítica (SAVIANI, 2008; 2009) no âmbito da Educação foi uma referência muito importante para a construção de uma pedagogia crítica da Educação Física brasileira.

Nos artigos investigados, identificamos referências diretas ao trabalho de Saviani e à sua concepção educacional (CASTELLANI FILHO, 1983; MIYAGIMA, 1989; GHIRALDELLI JÚNIOR, 1990a; PALAFOX, 1993; RESENDE, 1994; ESCOBAR, 1995; OLIVEIRA, 2001; PINA, 2008). Castellani Filho (2009) ratificou essa influência ao descrever a história que resultou na publicação do livro que é uma das principais expressões da pedagogia histórico-crítica na Educação Física brasileira: Metodologia do ensino de Educação Física (SOARES et al., 1992), ${ }^{1}$ escrito por um "Coletivo de Autores". Seria função de essa pedagogia promover:

[...] a clareza dos determinantes sociais da educação, a compreensão do grau em que as contradições da sociedade marcam a educação e, consequentemente, como 0 educador deve posicionar-se diante dessas contradições e desenredar a educação das visões ambíguas, para perceber claramente qual é a direção que cabe imprimir à questão educacional. Aí está o sentido fundamental do que chamamos pedagogia histórico-crítica. (SAVIANI, 2008, p. 100).

Saviani $(2008,2009)$ situa o surgimento dessa pedagogia como alternativa, no campo da Educação, por um lado, às teorias não críticas, por outro, às crítico-reprodutivistas. Nas teorias não críticas da Educação, Saviani (2008; 2009) incluiu as pedagogias tradicional, escolanovista e tecnicista. Essa caracterização, inicialmente apresentada no livro Escola e democracia, repercutiu fortemente na Educação Física. Soares (1988), baseando-se nesse livro, afirma que a disciplina vinha sendo influenciada:

[...] por construções teóricas que a reduzem a um biologismo ou a um
biopsicologismo, construções estas que nos permitem situá-las no quadro
das teorias não críticas da educação (pedagogia tradicional, pedagogia nova e
pedagogia tecnicista), podendo, a partir desta análise, ser entendida como algo
autônomo em relação à sociedade, como algo que acontece independente dos
sujeitos e da realidade concreta, fornecendo deste modo elementos para que a
consideremos, pelo modo como tem se organizado na escola brasileira, como uma
forma a-histórica de relação com o mundo. (SOARES, 1988, p. 21).

Essa "forma a-histórica de relação com o mundo" expressa aquilo que, segundo Saviani (2008; 2009), é característico das teorias tradicionais: não considerar os condicionantes histórico-sociais da Educação. Nesse sentido, essas teorias seriam, "[...] pois, ingênuas e não-críticas, já que é próprio da consciência crítica saber-se condicionada, determinada objetivamente, materialmente, ao passo que a consciência ingênua é aquela que não se sabe condicionada" (SAVIANI, 2009, p. 57). Ao contrário dessa perspectiva, Saviani (2010, p. 71)

10 próprio Castellani Filho, conforme seu depoimento (CASTELLANI FILHO, 2009), foi aluno de Saviani no Programa de Pós-Graduação em Educação da PUC/SP, considerado o "berço" da pedagogia histórico-crítica. 
pretendeu com sua pedagogia revolucionária sinalizar o caráter histórico da Educação, "[...] contrapondo de certa forma com o significado a-histórico das teorias não críticas".

Em Mazo e Goellner (1993, p. 65), está manifesto o que se tornou a tônica de certos textos no campo da Educação Física a partir dos anos 1980: a necessidade de que "[...] a análise de uma corrente educacional não deve estar desvinculada do contexto social, político, econômico e cultural no qual se insere", já que "[...] o horizonte mais amplo, dentro do qual a aula de Educação Física obtém seu sentido" (TAFFAREL, 1993, p. 45). Nesse contexto, chamam a atenção onze artigos que denunciam, por um lado, visões acríticas, a-históricas e ingênuas na Educação Física e, por outro, defendem a necessidade de a disciplina fomentar práticas engajadas, políticas, conscientes, críticas, em suma, preocupadas com os condicionantes sociais da tarefa educativa².

As teorias crítico-reprodutivistas, mesmo considerando os condicionantes sociais da Educação, dedicam-se, conforme Saviani $(2008 ; 2009)$ as definiu, a "[...] tão somente [...] explicar o mecanismo de funcionamento da escola tal como está constituída. Em outros termos, pelo seu caráter reprodutivista, essas teorias consideram que a escola não poderia ser diferente do que é" (SAVIANI, 2009, p. 27). Saviani (2008; 2009) enquadra, neste grupo, três teorias: a) teoria do sistema de ensino como violência simbólica, cuja máxima expressão é o livro de Bourdieu e Passeron A reprodução: elementos para uma teoria do sistema de ensino; b) teoria da escola como aparelho ideológico do Estado, cujo principal representante seria Althusser; c) teoria da escola dualista, que tem como marco o livro de Baudelot e Establet, $A$ escola capitalista na França. Nos artigos que foram fonte para nossa investigação, identificamos menção, apenas, à tese da escola como aparelho ideológico de Estado (FERREIRA NETO, 1989, LACKS, 1993, MAZO; GOELLNER, 1993; CASTELLANI FILHO, 1983), mas com o intuito de criticá-la. Chagas (1989, p. 103) foi direto ao ponto:

Porém, buscamos através de uma postura crítica e compromissada, superar a visão crítico-reprodutivista althusseriana que não visualiza formas de contrapor valores dominantes. Esta superação pressupõe a crença na força coletiva dos homens enquanto construtores de sua história e, consequentemente, da história da humanidade: a formação da consciência crítica, o compromisso político e a competência técnica daqueles que lutam pela transformação de um determinado estado de coisas.

Antes mesmo de Chagas, o texto de Castellani Filho $A$ (des)caracterização profissionalfilosófica da Educação Física, publicado no mesmo ano (1983) de Escola e democracia (de Dermeval Saviani), alertava para os limites das teorias crítico-reprodutivistas em favor da pedagogia histórico-crítica:

Mas, para que não se saia do 'teatro' com a incômoda sensação de impotência, que poderia ser causada pelos fatos acima expostos, importante é termos em mente, como Saviani, que 'longe de entendermos a Educação como determinante principal das transformações sociais, reconhecemos ser ela elemento secundário e determinado. Entretanto, longe de pensar, como o faz a concepção crítico-reprodutivista, que a Educação é determinada unidirecionalmente pela estrutura social, dissolvendo-se a sua especificidade, entendemos que a Educação se relaciona dialeticamente com a sociedade. Nesse sentido, ainda que o elemento determinado, não deixa de influenciar o elemento determinante. Ainda que secundário, nem por isso deixa de

2 Esses discursos, em sua maioria enfatizando os condicionantes socioeconômicos da Educação, estiveram presentes não só entre os anos 1980 e 1990 (MOREIRA, 1986; BRACHT, 1986; FREITAS; CARDOSO FILHO, 1988; ESCOBAR, 1988; FERREIRA NETO, 1989; WIGGERS et al., 1990; TAFFAREL, 1990, 1998/1999; PALAFOX, 1993), mas continuam sendo reproduzidos em textos dos anos 2000 (MICHELOTTI; SOUZA, 2008; DIAS, 2010). 
ser instrumento importante e por vezes decisivo no processo de transformação da sociedade (CASTELLANI FILHO, 1983, p. 100).

Considerando, ainda conforme Saviani (2009, p. 28), que a classe dominante não tem interesse na transformação histórica da escola, pois "[...] está empenhada na preservação do seu domínio, portanto, apenas acionará mecanismos de adaptação que evitem a transformação", a educação deveria ser criticada como distorcida pelos interesses dessa classe contra a classe dominada, com o currículo "atravessado" por uma visão ideológica da sociedade e a pedagogia reforçando aspectos reprodutores da estrutura social. Identificamos vinte textos denunciando essa dimensão conservadora e/ou ideológica da escola e, por consequência, da Educação Física. Esse discurso foi observado, sobretudo, nos artigos dos anos 1980 e 1990, embora continue presente na década seguinte (BRACHT, 1986; SOARES, 1988; FREITAS; CARDOSO FILHO, 1988; MONTALVÃO FILHO, 1988; LACKS, 1993; ESCOBAR, 1995; RIGO, 1995; TAFFAREL, 2001; SILVA, 2004).

Seria função de uma pedagogia crítica desvelar a dimensão ideológica da escola e, ao mesmo tempo, apresentar-se como alternativa de uma educação e de um currículo que, a partir dos interesses da classe dominada, representasse uma visão libertadora, democrática, justa e igualitária, pois não "corrompida" pelos interesses ideológicos das classes dominantes. Segundo a interpretação de Silva (1993), pode-se dizer que nessa característica está o essencial da moderna teorização crítica em educação. Para tanto, seria obrigação de sua pedagogia desvelar a ideologia dominante, olhando "por detrás" dela, com o propósito de demonstrar o papel da escola na legitimação de uma sociedade cindida em classes. Como expressão dessa incumbência é que detectamos termos e/ou conceitos que indicam a noção de ideologia como uma representação que oculta, ofusca, distorce, encobre, inverte, em suma, que implica em falsa interpretação da realidade (BRACHT, 1986; WIGGERS, 1988; FREITAS; CARDOSO FILHO, 1988; CHAGAS, 1989; RIGO; CHAGAS, 1990; MAZO; GOELLNER, 1993; PALAFOX, 1993; OLIVEIRA, 2001; SILVA, 2001).

A compreensão da ideologia como falsa consciência ou, então, como visão distorcida do real, decorria de um realismo forte que pressupõe a existência de dois níveis de avaliação da realidade: um que não consegue ultrapassar a "aparência" dos fenômenos, e outro, mais "profundo", que desvela o real em sua materialidade, atingindo sua essência e totalidade. Novamente podemos notar, nesse quadro, a influência da perspectiva inaugurada por Saviani (2010, p. 53), pois, para ele, "El papel de la ciência, de la teoria, es el de elaborar los conceptos que permitan traspassar las apariencias de la realidade para descubrir el movimento concreto". $\mathrm{Na}$ pedagogia crítica da Educação Física, esse empenho realista também reverberou (ESCOBAR, 1988; CAVALCANTI; BASSOLI, 1989; CASTRO, 1989; CAVALCANTI; BASSOLI, 1989; MOCKER, 1992; TAFFAREL, 1993, 1995; RIGO, 1995; ALBUQUERQUE et al., 2007; SOUZA, 2007; MICHELOTTI; SOUZA, 2008). ${ }^{3}$

A necessidade de se alcançar o real em sua "materialidade" foi acompanhada, nos artigos investigados, de uma crítica ao idealismo filosófico, pois, na interpretação de Taffarel (1995, p. 130),

A apreensão da realidade pode se dar sob a ótica de um abstrato sujeito cognoscente, de uma mente pensante que examina a realidade especulativamente - idealismo, onde prevalecem representações da realidade, pseudoconceito - ou

3 Reverberou e reverbera ainda hoje, conforme demonstram Almeida e Vaz (2010) e Almeida, Bracht e Vaz (2012). 
na ótica de um indivíduo histórico que exerce a sua atividade prática no trato com o conhecimento, dentro de determinadas relações, buscando destruir o mundo da pseudoconcreticidade, respondendo assim à crise orgânica do processo civilizatório. ${ }^{4}$

Ainda segundo esse diagnóstico, a perspectiva idealista tem prevalecido na área, de modo que deveríamos questionar essas "representações" de mundo que fragmentam a ciência e a filosofia e desconsideram as leis e categorias do pensamento dialético, pois " $\mathrm{A}$ dialética materialista [...] é a que mais dá condições de compreender a totalidade do real, em seus aspectos objetivos e subjetivos" (LACKS, 1993, p. 39). Nesse contexto, orientações que consideram os condicionantes sociais da educação seriam materialistas, aquelas que não os observam seriam idealistas, pois "[...] teorizam sobre Educação Física e Esportes fora do marco sócio-economico e cultural” (TAFFAREL, 1995, p. 126). Essa avaliação está também no trabalho de Saviani $(2008,2009)$, quando associa Pedagogia Tradicional e Pedagogia da Escola Nova, por um lado, às perspectivas idealistas e, por outro, aos interesses da burguesia.

Em outros textos, encontramos mais razões para a crítica ao idealismo, porque essa orientação: "[...] interpreta idealmente, subjetivamente, a natureza e a sociedade" (CAVALCANTI; BASSOLI, 1989, p. 12); acredita "[...] revolucionar a Educação Física apenas e tão somente através de transformações conceituais" (CASTELLANI FILHO, 1993, p. 124); negaria a historicidade e a capacidade de homens e mulheres interferirem na sociedade como agentes de transformação (MAZO; GOELLNER, 1993); "[...] ignora os condicionamentos sociais da ação e reação para centrar-se no sujeito como ser isolado, autônomo e não-social" (FRIZZO, 2008, p. 162); "[...] radica no fato de que o universo é composto de ideias que, de uma ou outra maneira, sempre se antepõem ao real (PALAFOX, 1993, p. 30); ou ainda porque seria essa teoria "[...] cética e reacionária, [...] prega(ndo) a ideia de que o mundo é incognoscível, isto é, que não pode ser conhecido pelo cérebro humano" (PALAFOX, 1993, p. 31). Ainda de acordo com Palafox (1993, p. 33), "A realidade objetiva existe independentemente de nossa consciência que a reflete (a natureza é o dado primário e a consciência, derivado do primeiro)". Seria tarefa daqueles que operam no âmbito da pedagogia crítica trabalhar "[...] na compreensão e aplicação crítico-social das teses fundamentais do materialismo junto à desmistificação de bases e práticas dos seguidores do idealismo" (PALAFOX, 1993, p. 34-35).

Treze dos artigos analisados nos levam a entender que, operando nos marcos do idealismo, não conseguiríamos alcançar mais do que uma pseudoeducação física escolar, sua "pseudoconcreticidade" (RIGO; CHAGAS, 1990; RIGO, 1995; CHAGAS, 1989; TAFFAREL, 1994; 1995; ALBUQUERQUE et al., 2007). O idealismo não permitiria aquilo que é um traço marcante do pensamento crítico: a crítica à ideologia burguesa, pois ele próprio seria a expressão intelectual dessa classe. Com a perspectiva materialista, seria possível, todavia, descobrir "o que é Educação Física" (ESCOBAR, 1988, p. 63), alcançar "o conhecimento objetivo da verdade" (TAFFAREL, 1995), uma "práxis verdadeiramente humana" (MAZO; GOELLNER, 1993) ou "verdadeiramente científica" (CAVALCANTI; BASSOLI, 1989, p. 15); identificar a "verdadeira identidade da Educação Física" (CASTELLANI FILHO, 1983, p. 95; CAVALCANTI, 1989) ou sua "verdadeira função social" (BRUEL, 1989); obter uma "[...] nova ordem social, calcada em princípios verdadeiramente democráticos e fiéis à verdade histórica" (MEDINA; SOARES; TAFFAREL, 1993); ou, então, chegar ao que Ghiraldelli Júnior (1990b, p. 198) almejava: 
"[...] sequenciar uma verdadeira prática onde os elementos transformadores inerentes ao movimento possam vir à tona para subalternizar os elementos meramente reprodutores". Esse afã pela "verdade", entendida como algo oposto ao conhecimento "contaminado" pela ideologia burguesa, está em consonância com o que Saviani (2010, p. 115-116) advogou em relação a uma perspectiva político-crítica. Segundo ele, essa posição

\begin{abstract}
[...] transformadora, de esquerda, não precisa de doutrinação porque a verdade está de seu lado (já disse que a verdade é sempre revolucionária). ${ }^{5}$ Portanto, aquilo de que se trata é de um trabalho de desvelamento, isto é, de mostrar a verdade com toda a sua força, ou, como se diz correntemente, a verdade nua e crua, doa a quem doer. A posição conservadora é que, por não ter mais a verdade do seu lado, necessita doutrinar, ou seja, fazer valer o argumento da fé, da autoridade, do natural, isto é, inexplicável racionalmente, para se manter. (SAVIANI, 2010, p. 115-116),
\end{abstract}

Num dos prefácios de Escola e democracia, referindo-se ao Capítulo 2 do livro, Saviani (2009, p. XXVI) afirma que "[...] não se trata de uma exposição exaustiva e sistemática, mas da indicação de caminhos para a crítica do existente e para a descoberta da verdade histórica."

Associada à tarefa de "mostrar a verdade com toda a sua força" ou, então, "descobrir a verdade histórica", a denúncia da alienação é outro objetivo recorrente nos textos da pedagogia crítica em Educação Física. Isso não poderá ser aqui explorado. Nossa opção, em vez disso, é interpretar a crítica à ideologia, tarefa essencial da pedagogia crítica em educação (SILVA, 1993) em textos da Educação Física. Para tanto, revisitaremos alguns usos desse conceito em Marx e Engels.

\title{
3 CRÍTICA À IDEOLOGIA NA EDUCAÇÃO FÍSICA: INTERPRETANDO CERTA RECEPÇÃO MARXISTA
}

\begin{abstract}
A história da natureza, a assim chamada ciência natural, não nos diz respeito aqui; mas, quanto à história dos homens, será preciso examiná-la, pois quase toda a ideologia se reduz ou a uma concepção distorcida dessa história ou a uma abstração total dela. A ideologia, ela mesma, é apenas um dos lados dessa história (MARX; ENGELS, 2007, p. 87).
\end{abstract}

A história do conceito de ideologia remonta à França revolucionária. Atribui-se a Destrutt de Tracy, no livro Elementos da ideologia, o primeiro emprego do termo, entendido como uma nova ciência que estaria interessada na análise sistemática das ideias e representações (CHAUÍ, 1980; LÖWY, 1991). É especialmente com Marx, e na tradição por ele inaugurada, que o conceito alcançou novo status como instrumental crítico e como componente essencial de um sistema teórico. Foi também após Marx que o conceito assumiu conotações distintas, tanto no interior do marxismo (com Lênin, Lukács, Escola de Frankfurt, Gramsci, Althusser) como no âmbito de outras perspectivas teóricas, como as de Weber e Mannheim. Nosso foco não é o de entender os deslocamentos que a noção de ideologia assumiu pós-Marx, mas antes demonstrar de que modo a versão da pedagogia crítica com a qual dialogamos reproduz a concepção de ideologia que tem origem nos registros do filósofo. Para realizar essa tarefa, além de Marx e Engels (2007), vamos tomar como referência as interpretações que dele nos oferecem Ricoeur (1990a, 1990b) e Thompson (1995). 
Tanto Thompson como Ricoeur avaliam que os escritos de Marx não apresentam uma perspectiva única a respeito do termo. Thompson (1995) discrimina três conceitos de ideologia nos filósofos alemães. Um chamado de "polêmico": "[...] ideologia, nesse sentido, é uma doutrina teórica e uma atividade que olha erroneamente as ideias como autônomas e eficazes e que não consegue compreender as condições reais e as características da vida sócio-histórica" (THOMPSON, 1995, p. 51). Outro identificado como concepção "epifenomênica", segundo a qual um sistema de ideias expressa os interesses da classe dominante, representando as relações de classe de forma ilusória. A terceira elaboração, adjetivada de "latente", trata-se de "[...] um sistema de representações que escondem, enganam, e que, ao fazer isso, servem para manter as relações de dominação" (THOMPSON, 1995, p. 75).

Essas "maneiras" de ler a ideologia, ainda segundo Thompson (1995), atribuem ao conceito, em Marx e Engels (2007), um sentido negativo, crítico ou pejorativo. Nessas circunstâncias, ideologia expressa sempre uma condição parcial. Atrelada a essa compreensão está o pressuposto de que a ideologia é uma forma de pensamento que expressa uma incapacidade de "ver" a realidade (e a dominação) em toda a sua extensão.

Essas definições ajudam a interpretar os usos da ideologia nos textos da Educação Física. Também neles ideologia tem esse sentido crítico, seja para denunciar a função da escola ou do esporte como sistema que expressa os interesses da classe dominante (concepção "epifenomênica"), seja para fazer a crítica das "representações" dominantes como falsas ou como oferecendo uma visão parcial do real ("concepção latente"). Desmascarar essa forma de consciência, ofício do pedagogo crítico, é mostrar que é errada ou que não tem justificação racional, implicando:

[...] não apenas que ela pode ser explicada com referência a condições socioeconômicas, mas também que ela interpreta mal essas condições, ou que ela não tem outra justificação a não ser o fato, empiricamente demonstrável, de expressar interesses particulares de grupos cujas posições são determinadas por essas condições (THOMPSON, 1995, p. 56).

Além disso, a crítica que a pedagogia crítica endereça às perspectivas "idealistas" pode ser lida a partir do uso "polêmico" de ideologia, pois o idealismo seria uma perspectiva que hiperdimensiona o valor e o papel das ideias na história e na vida social, de modo a não ver, como o materialismo histórico-dialético permitiria, as conexões entre suas ideias e as condições sócio-históricas. Segundo nos ensinam Marx e Engels (2007), é apenas onde se encerra a especulação, na vida real, que começa a ciência real, positiva, e a exposição da atividade prática, do processo prático de desenvolvimento dos homens. Nessas condições, "As fraseologias sobre a consciência acabam e o saber real tem de tomar o seu lugar" (MARX; ENGELS, 2007, p. 95).

Ricoeur (1990a, 1990b) oferece-nos mais uma leitura para compreender o sentido de ideologia nos textos aqui descritos. Para ele, a ideologia em Marx é entendida como uma imagem invertida e distorcida do que é o real. Assim, ele avalia que o conceito de ideologia, em Marx, se opõe menos à ciência do que à realidade. Ricouer (1990a, 1990b) se reporta a uma famosa metáfora utilizada por Marx e Engels (2007, p. 94) em A ideologia alemã:

Se, em toda ideologia os homens e suas relações nos aparecem situados com a cabeça para baixo como numa câmera escura, este fenômeno decorre do seu processo histórico de vida, da mesma forma como a inversão dos objetos na retina resulta de seu processo de vida imediatamente físico. 
Para Ricoeur (1990a; 1999b), é esse tipo de texto que tem um papel definidor no marxismo ortodoxo. Essa recepção assumiu a tese, presente em $A$ ideologia alemã, de que o ideológico é aquilo que é oposto ao real, um mundo de sombras incapaz de alcançar a essência ao oferecer uma representação falsa da realidade. Conforme as palavras de Ricouer (1990a, p. 73),

O que Marx tenta pensar, a partir desse modelo, é um processo geral pelo qual a atividade real, 0 processo de vida real, deixa de constituir a base, para ser substituído por aquilo que os homens dizem, se imaginam, se representam. A ideologia é esse menosprezo que nos faz tomar a imagem pelo real, o reflexo pelo original. ${ }^{6}$

Em circunstâncias como essas, de deformação da realidade, a função da crítica é operar uma inversão da reversão, restabelecendo, assim, o concreto ou o real em substituição à sua representação/interpretação. Conforme a leitura de Ricoeur (1999b, p. 95), nessas circunstâncias a crítica é uma redução do conceito à sua base concreta de existência, pois "Alguma coisa foi invertida na consciência humana e temos de inverter a inversão; este é o procedimento da crítica". Marx e Engels estão em "combate" (em A ideologia alemã) não com Hegel, mas com os jovens hegelianos de esquerda, pois, segundo os pensadores alemães, "A nenhum desses filósofos ocorreu a idéia de perguntar sobre a conexão entre a filosofia alemã e a realidade alemã, sobre a conexão de sua crítica com seu próprio meio material" (MARX; ENGELS, 2007, p. 84). Nesse trecho, de acordo com Ricoeur (1999b), material é sinônimo de real, assim como ideal é o mesmo que imaginário/representação. Essa passagem ajuda a entender a undécima sentença que Marx (2007) dirige a Feuerbach, segundo a qual os filósofos, até então, se limitaram a interpretar o mundo de diferentes maneiras, quando o que importa é transformá-lo a partir das condições materiais de sua existência. As representações, pensamentos ou conceitos (as "fraseologias" a que Marx e Engels se referem em A ideologia alemã) são ilusões da consciência e, nesse sentido, ideológicas. Em outra passagem, Ricoeur (1999b, p. 175) novamente se refere à dualidade real/representação para a explicação do conceito de ideologia em Marx:

Para Marx, ideológico é o que é refletido por meio de representações. É o mundo da representação por oposição ao mundo histórico, tendo este último uma consistência própria graças à actividade, às condições de actividade, à história das necessidades, à história da produção, etc. 0 conceito de realidade cobre todos os processos que podem ser descritos sob o título de materialismo histórico.

De modo contrário, Marx e Engels (2007) sugerem uma "elevação da terra ao céu" em vez de uma "descida do céu à terra", quer dizer, não se trata de partir, como querem os hegelianos de esquerda, daquilo que os homens

[...] dizem, imaginam ou representam, tampouco dos homens pensados, imaginados e representados para, a partir daí, chegar aos homens de carne e osso; parte-se dos homens realmente ativos e, a partir de seu processo de vida real, expõe-se também o desenvolvimento dos reflexos ideológicos e dos ecos desse processo de vida. Também as formações nebulosas na cabeça dos homens são sublimações necessárias de seu processo de vida material, processo empiricamente constatável e ligados a pressupostos materiais. A moral, a religião, a metafísica e qualquer outra ideologia, bem como as formas de consciência a elas correspondentes, são privadas, aqui, da aparência de autonomia que até

6 Ainda segundo Ricoeur (1990a, p. 83), as metáforas que Marx emprega para se referir à discussão sobre o conceito de ideologia permanecem atreladas a um feixe de imagens especulares e a um sistema de oposições binárias: "[...] teoria-prática, real-imaginário, luz-obscuridade, que atestam a pertença metafísica do conceito de ideologia enquanto inversão de uma inversão". 
então possuíam. [...] Tão logo seja apresentado esse processo ativo de vida, a história deixa de ser uma coleção de fatos mortos, como para os empiristas ainda abstratos, ou uma ação imaginária de sujeitos imaginários, como para os idealistas (MARX; ENGELS, 2007, p. 94-95).

Visto que a ideologia é o oposto das condições reais da vida material ou, então, imagem invertida, parcial e distorcida do que é o real, a interpretação de Ricoeur também ajuda a entender a crítica que a pedagogia marxista ${ }^{7}$ aqui analisada produziu em relação ao que identificou como perspectivas idealistas. O resultado foi a oposição, segundo Ricoeur (1999b), comum ao marxismo ortodoxo, que opõe materialismo e idealismo, como se pudéssemos escolher entre um e outro para explicar o mundo. Se não é um materialista histórico, é idealista; se não estamos de um lado, estamos necessariamente do outro. Sem o materialismo histórico, não é possível captar o real em sua essência, mas apenas em sua aparência (a pseudoconcreticidade). $\mathrm{Na}$ primeira parte deste texto, mostramos como esse raciocínio esteve presente na Educação Física brasileira.

\section{CONSIDERAÇÕES FINAIS}

Nossa descrição, diferentemente de outras que também se debruçaram sobre o discurso crítico do Movimento Renovador da Educação Física brasileira, visou a uma análise de caráter mais epistemológico de sua pedagogia. Sabemos que esse discurso não se resumiu aos textos aqui descritos, aos autores citados nem às revistas tomadas em investigação. Além disso, é preciso dizer que muitos dos autores que tiveram suas produções vinculadas à pedagogia marxista em análise abandonaram esse referencial ao se identificarem com outras tradições teóricas; algumas delas ligadas ao marxismo, outras distantes do materialismo histórico-dialético.

Os resultados demonstram o modo pelo qual a pedagogia histórico-crítica (SAVIANI, 2008; 2009) foi vital para o surgimento de uma perspectiva crítica no âmbito da Educação Física brasileira. Evidenciam, também, que a presença dessa tradição foi muito marcante até meados da década de 1990, quando os textos de autores vinculados a essa orientação teórica, então hegemônica, tornam-se menos recorrentes. Apesar disso, alguns autores continuam, nos anos 2000, empregando conceitos vinculados àquela orientação crítica, utilizando, portanto, um vocabulário que valoriza, prioritariamente, os aspectos macroeconômicos que afetam a educação (em alguns casos, tudo se resume à luta de classes), argumentando a respeito do papel ideológico e alienante da escola ou do esporte em uma sociedade de classes, contrapondo teorias críticas a outras que seriam a-históricas, ingênuas e acríticas, afirmando o materialismo como "a" melhor referência a nos oferecer uma leitura correta do mundo, defendendo a necessidade de uma crítica à ideologia dominante e de suas manifestações no plano do conhecimento. Dessas manifestações, mostramos como ela resultou em uma crítica ao idealismo filosófico, por ser essa tradição incapaz de oferecer uma leitura adequada, no sentido de mais verdadeira, da realidade e, claro, da Educação Física escolar. Nesse procedimento, a pedagogia crítica retomou, de modo esquemático, a crítica que Marx e Engels (2007) endereçaram aos hegelianos de esquerda.

7 Com Almeida e Vaz (2013), chamamos de pedagogia marxista aquela perspectiva educacional que, desde a década de 1980, fundamenta suas reflexões na obra de Marx e na tradição que dela se desenvolveu. Conforme já dissemos, temos clareza que, em Educação e na Educação Física, há marxismos e marxismos, de modo que este artigo dialoga com uma determinada interpretação desta tradição, representada pelos autores que aqui referenciamos. 
É interessante destacar, a esse respeito, que o dualismo realidade/aparência tem ocupado essa versão da pedagogia crítica da Educação Física desde os anos 1980. Hoje essa preocupação se atualizou, como mostraram Almeida e Vaz (2010) e Almeida, Bracht e Vaz (2012), em outro contexto, na crítica que essa pedagogia endereça ao "pós-modernismo" e ao "antirrealismo" pressupostos nas correntes que assumiram, em filosofia, a virada linguística. 0 argumento é o mesmo: essas perspectivas não permitem desvelar o que a realidade, de fato, é, implicando em sua incognoscibilidade. Não surpreende a pecha de modismo, irracionalismo e conservadorismo ${ }^{8}$ associada a essas orientações teóricas e à defesa de um "giro" ou "virada ontológica", pois somente assim a morte do "real" ou do "concreto" seria evitada e a Educação Física, em sua "essência" ou "totalidade", poderia ser teorizada.

Com a ajuda de Thompson (1995) e Ricoeur (1990a; 1990b), também oferecemos uma interpretação sobre os fundamentos da crítica à ideologia no âmbito da pedagogia analisada. Com eles, vimos que a noção de ideologia com a qual a pedagogia crítica opera é bastante problemática. ${ }^{9}$ Para Thompson, por exemplo, essa interpretação de ideologia nos leva a pensá-la como um conjunto de ideias ou representações que refletem de modo inadequado a realidade social. Essa leitura pressupõe um "realismo forte" que é bastante questionável na Filosofia contemporânea. ${ }^{10}$ Ricoeur, por sua vez, argumenta que essa noção de ideologia pressupõe a existência de um ponto de vista que seja capaz de escapar à condição ideológica do conhecimento, situação a partir da qual se poderia afirmar que a verdade está de um lado e o conhecimento falso do outro, normalmente o do seu oponente. 0 crítico da ideologia estaria, assim, livre da suspeita que ele próprio denuncia. É por isso que ele pergunta: "[...] será que a teoria social, concebida como crítica, pode aceder a um estatuto inteiramente não-ideológico, segundo seus próprios critérios de ideologia?" (RICOUER, 1990a, p. 81). A essa pretensão, acrescenta-se outra: não apenas é possível esse lugar não ideológico, mas ele é ocupado pela ciência. Em Marx, esse contrário não existia, mas, quando o marxismo se consolida como teoria em vez de "coleção de escritos", e, em alguns casos, como uma doutrina científica, fornece, então, o oposto da ideologia: o marxismo como ciência ou como expressão da verdade na história, afinal, a verdade está inscrita na história, ao menos conforme Saviani (2008), e é o marxismo que oferece a leitura correta dessa história.

Assumimos que o "campo crítico" é, hoje, marcado por uma pluralidade de perspectivas teóricas e políticas não restrita apenas ao marxismo demarcado pela pedagogia histórico-crítica (que continua atuante na área). Essa diferenciação aconteceu porque a própria referência marxista se tornou, na Educação Física, mais matizada. Além disso, outras orientações teóricas passaram a circular no campo. Essas novas tradições, pelo menos em relação ao conceito de ideologia como empregado nos escritos aqui analisados, operam com ferramentas conceituais que, embora críticas, são distintas daquelas empregadas pelo marxismo (da pedagogia histórico-crítica) que fundamentou tantos textos publicados entre 1979 e 2010. Com isso, muda o sentido de intelectual crítico e de sua tarefa.

8 Também aqui a pedagogia crítica da Educação Física não procede de modo diferente à estratégia de desqualificação identificada em Saviani (2008, 2009), pois esse autor também usa o termo "pseudocientífico" para se referir aos métodos novos ou, segundo sua avaliação, aos modismos em educação (em seu caso, como já mencionado, o escolanovismo e a pedagogia tecnicista).

9 Embora não tratemos disso no artigo, nossos intérpretes, cada um ao seu modo, defenderam uma concepção diferente de ideologia, propondo uma reformulação do seu conceito e, consequentemente, da crítica ideológica no contemporâneo.

10 Filósofos como Rorty nos incitam a tentar superar, em Filosofia, o vocabulário dualista que redunda no "realismo forte". Esse é pressuposto no discurso crítico da Educação Física. Conforme as palavras do autor, deveríamos insistir "[...] que o modo como uma coisa é em si própria não existe, [que não existe] qualquer descrição para além de qualquer uso que o ser humano lhe queira dar. A vantagem de insistir nestes pontos é que qualquer dualismo que encontremos, qualquer divisão que encontremos um filósofo a querer preencher ou ligar, pode fazer-se com que pareça uma simples diferença entre dois conjuntos de descrições do mesmo grupo de coisas. 'Poder fazer-se de modo a que pareça' não contrasta neste contexto com o que 'realmente é'. Não é como se houvesse um procedimento para descobrir se estamos de facto a lidar com dois grupos de coisas ou com um. A coisa em si, a identidade, depende da descrição" (RORTY, 1999, p. 19-20). 
Somos movidos, então, pelo desejo de reconstruir a tarefa da crítica no âmbito da Educação Física. Essa redescrição pressupõe não apenas recuperar a tradição crítica da área, mas o enfrentamento de questões como: seus pressupostos "originais" se sustentam à luz das críticas já endereçadas a eles (por outras teorias) ou, então, quando consideramos os atuais condicionantes histórico-sociais da Educação? Qual o significado que assumiria, hoje, a crítica à ideologia na discussão pedagógica? É possível alguma unidade em meio ao pluralismo identificado? Em que bases pode-se sustentar o caráter normativo da tradição crítica? Quais as demandas que os novos desdobramentos teóricos (e políticos) apresentam a essa pedagogia? Esses são desafios para o porvir.

\section{REFERÊNCIAS}

ALBUQUERQUE, Joelma et al. A prática pedagógica da educação física no MS: possibilidades de articulação entre teoria pedagógica, teoria do conhecimento e projeto histórico. Revista Brasileira de Ciências do Esporte, Campinas, v. 28, n. 2, p. 121-140, 2007.

ALMEIDA, Felipe Quintão de; BRACHT, Valter; VAZ, Alexandre Fernandez. Classificações epistemológicas na educação física... redescrições. Movimento, Porto Alegre, v. 18, n. 4, p. 241-263, 2012.

ALMEIDA, Felipe Quintão de; VAZ, Alexandre Fernandez. Richard Rorty e a filosofia da educação: uma análise da recepção marxista. Educação e Realidade, v. 38, n.1, p. 249-270, 2013.

BARDIN, Laurence. Análise de conteúdo. Portugal: Edições 70, 1977.

BRACHT, Valter. A criança que pratica esportes respeita as regras do jogo... capitalista. Revista Brasileira de Ciências do Esporte, São Paulo, v. 7, n. 2, p. 62-68, jan. 1986.

BRUEL, Maria Rita. Função social do esporte. Motrivivência, Florianópolis, n. 2, p. 108-111, jun. 1989.

CASTELLANI FILHO, Lino. A cultura corporal em questão. In: CASTELLANI FILHO, L. et al. Metodologia do ensino de educação física. São Paulo: Cortez, 2009. p. 184-198.

CASTELLANI FILHO, Lino. A (des)caracterização profissional-filosófica da educação física. Revista Brasileira de Ciências do Esporte, São Paulo, v. 4, n. 3, p. 95-101, maio 1983.

CASTELLANI FILHO, Lino. A. Educação física/ciências do esporte no Brasil hoje: pelos meandros da educação física. Revista Brasileira de Ciências do Esporte, Maringá, v. 14, n. 3 , p. 119-125, maio 1993.

CASTRO, Iran Junqueira. Formação profissional de educação física em uma sociedade em transformação. Revista Brasileira de Ciências do Esporte, Campinas, v.10, n. 3, p. 34-37, maio 1989.

CAVALCANTI, Kátia Brandão. O papel dos grupos de estudo no desenvolvimento da ciência da motricidade humana. Motrivivência, Florianópolis, v. 2, n. 2, p. 95-96, jun. 1989. 
histórico-dialética. Motrivivência, Florianópolis, v. 1, n. 1, p. 12-15, jun. 1989.

CHAGAS, Eliane Pardo. Esporte de lazer - esporte de rendimento: análise de seus pressupostos. Motrivivência, Florianópolis, v. 2, n. 2, p. 101-104, jun. 1989.

CHAUÍ, Marilena. O que é ideologia. São Paulo: Brasiliense, 1980.

DIAS, Graziany Penna. Empreendedorismo e educação física: reflexões à sua apreensão/ implementação na formação humana. Motrivivência, Florianópolis, v. 35, n. 10, p. 147-165, 2010.

ESCOBAR, Micheli O. Cultura corporal na escola: tarefas da educação física. Motrivivência, Florianópolis, v. 8, n. 8, p. 91-102, dez. 1995.

ESCOBAR, Micheli O. Reformulação dos currículos de formação em educação física.

Motrivivência, Florianópolis, v. 1, n. 1, p. 63-67, dez. 1988.

FERREIRA NETO, Amarílio. Esporte escolar e oligarquia em Sergipe. Motrivivência, Florianópolis, v. 1, n. 2, p. 76-80, jun. 1989.

FREITAS, Francisco Mauri; CARDOSO FILHO, Joaquim Ignácio. Educação física: decapitação cultural e hegemonia imperialista. Revista Brasileira de Ciências do Esporte, São Paulo, v. 9, n. 2, p. 55-61, jan. 1988.

FRIZZO, Giovanni. O trabalho pedagógico como referência para a pesquisa em educação física. Pensar a Prática, Goiânia, v. 11, n. 2, p. 159-167, 2008.

GHIRALDELLI JÚNIOR, Paulo. Educação física e pedagogia: a questão dos conteúdos. Revista Brasileira de Ciências do Esporte, Campinas, v. 11, n. 2, p. 133-135, jan. 1990a.

GHIRALDELLI JÚNIOR, Paulo. Indicações para o estudo do movimento corporal humano da educação física a partir da dialética materialista. Revista Brasileira de Ciências do Esporte, Campinas, v. 11, n. 3, p. 197-200, 1990b.

LACKS, Solange. O cotidiano da educação física escolar e suas tendências. Motrivivência, Aracaju, v.6, n. 4, p. 36-40, jun. 1993.

LÖWY, Michel. Ideologias e ciência social: para uma análise marxista. São Paulo: Cortez, 1991.

MARX, Karl; ENGELS, Friedrich. A ideologia alemã. São Paulo: Boitempo, 2007.

MAZO, Janice Zarpellon; GOELLNER, Silvana Vilodre. Pensando a educação física humanista conservadora ou emancipatória? Motrivivência, Florianópolis, v. 4, n. 4, p. 65-71, jun. 1993.

MEDINA, João Paulo Subirá; SOARES, Carmen Lúcia Soares; TAFFAREL, Celi Nelza Zulque. Ação pedagógica da escola pela via da interdisciplinaridade. Motrivivência, Florianópolis, v. 4, n. 4, p. 55-64, jun. 1993.

MIYAGIMA, Cláudio. O esporte (des)educa. Motrivivência, Florianópolis, v. 1, n. 2, p. 31-34, jun. 1989.

MICHELOTTI, Daniele de Vargas; SOUZA, Maristela da Silva. Análise do conhecimento teóricometodológico dos professores em educação física do CEFD/UFSM em relação à sua prática pedagógica. Movimento, Porto Alegre, v. 14, n. 2, p. 63-82, 2008. 
MOCKER, Maria Cecília de Miranda. Educação física escolar, uma disciplina humanizante?

Revista Brasileira de Ciências do Esporte, Maringá, v. 13, n. 2, p. 293-295, jan. 1992.

MONTALVÃO FILHO, Arivaldo. Ponto de vista: educação física escolar e o compromisso com a escola. Motrivivência, Florianópolis, v. 6, n. 4, p. 93-99, jun. 1993.

MOREIRA, Wagner Wey. Educação física na escola de $1^{0}$ grau: $1^{\mathrm{a}}$ a $4^{\underline{a}}$ séries. Revista Brasileira de Ciências do Esporte, São Paulo, v. 7, n. 2, p. 75-79, jan. 1986.

OLIVEIRA, Cristina Borges de. Aproximações exploratórias sobre educação, educação física e sociedade: adversidades de um currículo. Pensar a Prática, Goiânia, v. 4, p. 99-114, 2001.

PALAFOX, Gabriel Humberto. As tendências pedagógicas em educação física e sua relação com as categorias idealistas e materialistas da história. Motrivivência, Florianópolis, v. 4, n. 4, p. 30-35, jun. 1993.

PINA, Leonardo Docena. Pedagogia histórico-crítica e transmissão do conhecimento sistematizado sobre o esporte na educação física. Motrivivência, Florianópolis, n. 31, p. 99-114, 2008.

RESENDE, Helder Guerra. Reflexões sobre algumas contradições da educação física no âmbito da escola pública e alguns caminhos didáticos pedagógicos na perspectiva da cultura corporal. Movimento, Porto Alegre, v. 1, n. 1, p. 20-28, 1994.

RICOEUR, Paul. Ideologia e utopia. Lisboa: Edições 70, 1990b.

RICOEUR, Paul. Interpretações e ideologias. Rio de Janeiro: Francisco Alves, 1990a.

RIGO, Luis Carlos. A educação física fora de forma. Revista Brasileira de Ciências do Esporte, Porto Alegre, v. 16, n. 2, p. 82-93, jan. 1995.

RIGO, Luis Carlos; CHAGAS, Eliane Pardo. Educação física escolar e reprodução social. Revista Brasileira de Ciências do Esporte, Campinas, v. 11, n. 3, p. 179-185, 1990.

RORTY, Richard. Ensaios sobre Heidegger e outros: escritos filosóficos 2. Rio de Janeiro: Relume-Dumará, 1999.

SAVIANI, Dermeval. Escola e democracia. São Paulo: Autores Associados, 2009.

SAVIANI, Dermeval. Interlocuções pedagógicas: conversa com Paulo Freire e Adriano Nogueira e 30 entrevistas sobre educação. São Paulo: Autores Associados, 2010.

SAVIANI, Dermeval. Pedagogia histórico-crítica: primeiras aproximações. São Paulo: Autores Associados, 2008.

SILVA, Maria Cecília de Paula. Educar para superar: uma reflexão sobre a educação física escolar. Pensar a Prática, Goiânia, v. 7, n. 2, p. 205-220, 2004.

SILVA, Tomaz Tadeu da. Sociologia da educação e a pedagogia crítica em tempos pósmodernos. In: SILVA, Tomaz Tadeu da (Org.). Teoria educacional crítica em tempos pósmodernos. Porto Alegre: Artes Médicas, 1993. p. 122-140.

SOARES, Carmen Lúcia. Fundamentos da educação física escolar. Revista Brasileira de Ciências do Esporte, São Paulo, v. 10, n. 1, p. 19-27, set. 1988. 
SOARES, Carme Lúcia et al. Metodologia do ensino da educação física. São Paulo: Cortez, 1992.

SOUZA, Maristela da Silva. Didática da educação física escolar e o processo lógico de apreensão do saber. Movimento, Porto Alegre, v. 13, n. 3, p. 181-199, 2007.

TAFFAREL, Celi Nelza Zulke. A carta de carpina educação física: novos compromissos: pedagogia, movimento, miséria. Revista Brasileira de Ciências do Esporte, Campinas, v. 23, n. 1, p. 41-55, 2001.

TAFFAREL, Celi Nelza Zulke. Concepções de aulas abertas a experiências em educação física: discussão de pressupostos em relação a fins e objetivos, à luz da realidade da educação física escolar brasileira. Motrivivência, Florianópolis, v. 6, n. 4, p. 41-46, jun. 1993.

TAFFAREL, Celi Nelza Zulke. A educação física em Pernambuco: quadro atual e perspectivas. Revista Brasileira de Ciências do Esporte, Campinas, v. 11, n. 3, p. 219-223, 1990.

TAFFAREL, Celi Nelza Zulke. Políticas públicas e educação física e esportes no Brasil: reformas ou ruptura? Entrevistador: Nivaldo Antônio David Nogueira com Celi Taffarel. Pensar a Prática, Goiânia, v. 2, p. 1-24, jan./jun.1998/1999.

TAFFAREL, Celi Nelza Zulke. Proposta para eixos orientadores de um curso de pós-graduação a nível de especialização em metodologia do ensino da educação física. Motrivivência, Florianópolis, v. 5, n. 5/7, p. 146-165, dez. 1994.

TAFFAREL, Celi Nelza Zulke. Referencial teórico-metodológico para produção do conhecimento sobre metodologia do ensino da educação física e esportes. Revista Brasileira de Ciências do Esporte, Porto Alegre, v. 16, n. 2, p. 122-133, jan. 1995.

THOMPSON, John. Ideologia e cultura moderna: teoria social crítica na era dos meios de comunicação de massa. Petrópolis, RJ: Vozes, 1995.

VAZ, Alexandre Fernandez; ALMEIDA, Felipe Quintão de. Do giro lingüístico ao giro ontológico na atividade epistemológica em educação física. Movimento, Porto Alegre, v. 16, n. 3, p. 11-28, 2010.

WIGGERS, Ingrid Dittrich. Currículo e ideologia: um estudo introdutório. Motrivivência, Florianópolis, v. 1, n. 1, p. 43-49, dez. 1988.

WIGGERS, Ingrid Dittrich et al. Didática da educação física: ordem unida, recreação e pedagogia do movimento crítico. Motrivivência, Florianópolis, v. 3, n. 3, p. 93-97, jan. 1990. 